\title{
The Effect of Light Intensity on the Production of Oat (Avena sativa L.) Doubled Haploids through Oat $\times$ Maize Crosses
}

\author{
E. SkrzyPeK*, M. WARChOŁ, I. CZyczyŁo-Mysza, I. MarcińsKa, A. NowaKowsKa, \\ K. DziurKa, K. Juzoń and A. NogA \\ Department of Biotechnology, The Franciszek Górski Institute of Plant Physiology, \\ Polish Academy of Sciences, Niezapominajek 21, 30-239 Kraków, Poland
}

(Received 30 December 2015; Accepted 26 January 2016;

Communicated by P.S. Baenziger)

\begin{abstract}
Oat haploid embryos were obtained by wide crossing with maize. The effect of light intensity during the growing period of donor plants $\left(450\right.$ and $\left.800 \mu \mathrm{mol} \mathrm{m}^{-2} \mathrm{~s}^{-1}\right)$ and in vitro cultures $\left(20,40,70\right.$ and $\left.110 \mu \mathrm{mol} \mathrm{m}^{-2} \mathrm{~s}^{-1}\right)$ was examined for the induction and development of oat DH lines. Oat florets (26008) from 32 genotypes were pollinated with maize and treated with 2,4-dichlorophenoxyacetic acid. All the tested genotypes formed more haploid embryos when donor plants were grown in a greenhouse (9.4\%) compared to a growth chamber $(6.1 \%)$. The light intensity of $110 \mu \mathrm{mol} \mathrm{m} \mathrm{m}^{-2} \mathrm{~s}^{-1}$ during in vitro culture resulted in the highest percentage of embryo germination (38.9\%), conversion into plants $(36.4 \%)$ and DH line production (9.2\%) when compared with lower light intensities $(20,40$ and $70 \mu \mathrm{mol}$ $\mathrm{m}^{-2} \mathrm{~s}^{-1}$ ). The results show that the growth conditions of the donor plant and light intensity during in vitro culture can affect the development of haploid embryos. This fact may have an impact on oat breeding programs using oat $\times$ maize crosses.
\end{abstract}

Keywords: embryos germination, wide crossing, DH lines

\section{Introduction}

Plant breeding is focused on continuously increasing crop production to meet the needs of an ever-growing world population and improving the quality food to ensure a long and healthy life. Biotechnology provides powerful tools for plant breeding, such as tissue culture, which includes particularly effective haploid and doubled haploid breeding methods that can effectively help select superior plants (Germana 2011). The production of haploids, which are plants with a gametophytic chromosome number, and doubled haploids (DH), i.e., haploids that have undergone chromosome duplication has become a central part of advanced plant breeding programmes. DH technologies are applied as powerful tools for the accelerated production of homozygous lines from heterozygous donor genotype without the necessity of selection in every generation. It takes approximately 10 years to produce commercial oat cultivar using conventional pedigree selec-

\footnotetext{
*Corresponding author; E-mail: e.skrzypek@ifr-pan.edu.pl; Phone: 4812425 1833; Fax: 484251844
} 
tion. Furthermore, the selection of desired traits is easier and more effective for DH lines that do not segregate over generations (Rubtsova et al. 2013).

The most commonly applied DH systems in oat (Avena sativa L.) are wide hybridization through interspecific crosses (Rines 2003; Sidhu et al. 2006; Marcińska et al. 2013; Ishii et al. 2013; Nowakowska et al. 2015; Warchoł et al. 2016) and the use of androgenesis in anther culture (Kiviharju 2009) or isolated microspore culture (Sidhu and Davies 2009). Wide crossing with maize (Zea mays L.) is most extensively applied in the commercial production of oat DH lines. The result of such crossing is either absent or highly abnormal endosperm and the embryo fails to fully develop. The application of synthetic auxins, such as dicamba or 2,4-dichlorophenoxyacetic acid (2,4-D), to pollinated florets stimulates haploid embryo development to the stage where embryos can be rescued on nutrient media. The disadvantages of the method include the need to perform the embryo rescue procedure, as the endosperm usually fails to develop in the caryopses and the isolated embryos must be cultivated on the regeneration medium. The germination period is a very critical stage in the development of haploid oat embryos. As described by Rines (2003), the percentage of embryo recovery usually ranges between 2 and $10 \%$ of maizepollinated oat florets. The rate of germination of these embryos into vigorous plants is typically low and falls below $20 \%$. This low efficiency makes it difficult to conduct experiments of adequate scope to statistically compare factors affecting the frequency of plant recovery.

Light is essential for plant growth and development, serving as an energy source for photosynthesis and as an environmental signal in photomorphogenesis. Light-mediated responses are most apparent in germinating seedlings, i.e., the period between embryo germination and the formation of the first true leaves (Chen et al. 2004).

Typically, haploid embryo germination in vitro is conducted in the dark for 1-2 days, and then in light. In the study of Rines (2003), rescued embryos were placed in a dark incubator until embryo germination was observed, at which time they were transferred to a cabinet with $12 \mathrm{~h}$ of $\sim 100 \mu \mathrm{E} \mathrm{m}^{-2} \mathrm{~s}^{-1}$ per day. Similar conditions were described by Sidhu et al. (2006), who kept embryos for 2 days in the dark and then transferred them to the light of $50 \mu \mathrm{E} \mathrm{m}^{-2} \mathrm{~s}^{-1}$ and 16-h photoperiod. Kiviharju et al. (2005) reported that the embryo-like structure inducted from oat anthers was incubated in the dark or under dim light conditions (approximately $40 \mu \mathrm{mol} \mathrm{m}^{-2} \mathrm{~s}^{-1}$ ) and 16-h photoperiod.

Nowakowska et al. (2015) and Warchoł et al. (2016) used only light conditions, without the dark period, for the germination of oat haploid embryos; the intensity of radiation in an in vitro chamber was about $100 \mu \mathrm{mol} \mathrm{m} \mathrm{m}^{-2}$ and $60 \mu \mathrm{mol} \mathrm{m} \mathrm{m}^{-2} \mathrm{~s}^{-1}$, respectively, and $16-\mathrm{h}$ photoperiod. The aforementioned studies focused only on light conditions in vitro for embryo germinations, but not the light required for donor plants. In wheat, Campbell et al. (1998) described the influence of light intensity on the effectiveness of haploid embryo production, taking into consideration the light conditions for donor plants. In that study, wheat donor plants were grown at one of three light intensities $(300,500$ or 1000 $\mu \mathrm{mol} \mathrm{m} \mathrm{m}^{-2} \mathrm{~s}^{-1}$ ). The highest light intensity resulted in the greatest frequency of haploid embryos, although the magnitude of this effect varied between cultivars. Differences in the germination rates of embryos grown under different conditions were not evident. 
Currently, there are no reports available on the effects of donor plant growth conditions and light intensity during embryo development on oat $\times$ maize wide crosses. Furthermore, the influence of light intensity on the formation and recovery of haploid embryos has not yet been investigated in oat $\times$ maize crosses.

The aim of this report was to investigate the importance of donor plant growth conditions for haploid embryo formation and the light intensity for haploid embryo germination as well as the subsequent development of haploid and DH lines in the selected Polish oat cultivars. This information will help optimize the growing conditions of donor plants and in vitro conditions for the development of haploid embryos and plants with the final aim of improving the efficiency of $\mathrm{DH}$ line production.

\section{Materials and Methods}

\section{Plant material}

In experiment 1 , oat plants from five genotypes ( $\mathrm{F}_{1}$ progeny): Scorpion $\times \mathrm{STH} 9-32, \mathrm{STH}$ 93-61 × DC 2112/05, SW 032609/06 $\times$ Bingo, STH $09251 \times$ Typhon and Breton $\times$ Zolak derived from Małopolska Plant Breeding Polanowice Ltd. and Danko Plant Breeding Ltd. were grown under controlled conditions in a growth chamber and a greenhouse. The growth chamber was maintained under 16-h photoperiod and photosynthetic active radiation (PAR) of $450 \mu \mathrm{mol} \mathrm{m} \mathrm{m}^{-2} \mathrm{~s}^{-1}$ (by high pressure sodium lamps, $400 \mathrm{~W}$; Philips SON-T AGRO, Belgium), and a temperature of $21 / 17^{\circ} \mathrm{C}$ day/night. In the greenhouse natural (solar) light intensity was $800 \mu \mathrm{mol} \mathrm{m} \mathrm{m}^{-2} \mathrm{~s}^{-1}, 16-\mathrm{h}$ photoperiod was sustained with the addition of high pressure sodium lamps ( $400 \mathrm{~W}$; Philips SON-T AGRO, Belgium) between 6-8 a.m., 6-10 p.m. and on cloudy days, in $40 \pm 5 \%$ and temperature was $21 / 17^{\circ} \mathrm{C}$ day/ night. Light intensity was measured with a QSPAR Quantum Sensor (Hansatech Instruments LTD, Kings Lynn, England).

In experiment 2 , oat plants from thirty-two oat genotypes $\left(\mathrm{F}_{1}\right.$ progeny): Bingo $\times$ Canyon, DC 2648/04 $\times$ Bingo, DH 1496/08 $\times$ STH 9-114, Flamingsgold $\times$ DC 3750/02, Gere $\times$ Flamingsgold, Husky $\times$ IDC 2112/05, Scorpion $\times$ STH 9-32, STH 8-50 $\times$ Canyon, STH 8-79 $\times$ Canyon, STH 93-61 $\times$ DC 2112/05, SW 032609/06 $\times$ Bingo, SW $090325 \times$ Breton, DH 1496/08 ×STH 9-32, SW $081202 \times$ Bingo, STH $09251 \times$ Typhon, Atego $\times$ Caracas, Typhon $\times$ Rajtar, Caracas $\times$ Zolak, Auron $\times$ Rajtar, Krezus $\times$ Aragon, Krezus $\times$ Kanton, Krezus $\times$ Zolak, Zuch $\times$ Gere, Breton $\times$ Zolak, Rajtar $\times$ Zolak, Milenium $\times$ Bingo, STH $9110 \times$ Bingo, STH $9110 \times$ Contender, STH $9787 \times$ Bingo, STH $7105 \times$ Contender, Akt $\times$ STH 97806 and Cacko $\times$ STH 97806, were obtained from Strzelce Plant Breeding Ltd., Małopolska Plant Breeding Polanowice Ltd. and Danko Plant Breeding Ltd. Plants were grown in the greenhouse under a light intensity and a temperature as in experiment 1.

In both experiments maize (Zea mays L. var. saccharata) mixture of three genotypes: MPC4, Dobosz and Wania was used as pollen donor. Maize plants were grown in the greenhouse at $21-28 / 17^{\circ} \mathrm{C}$ day/night and under light intensity as in experiment 1 .

All plants were fertilized with a liquid medium once a week (Hoagland and Arnon 1938). 


\section{Haploid plant production}

Oat doubled haploid lines were obtained through oat $\times$ maize crosses, according to the method described by Warchoł et al. (2016). The day after pollination of emasculated florets by maize, one drop of $100 \mathrm{mg} \mathrm{L}^{-1}$ 2,4-dichlorophenoxyacetic acid (2,4-D) was applied to each oat pistil. The embryos were isolated from enlarged ovaries 21 days after pollination and cultured on 190-2 medium (Wang and Hu 1984), whereas developed haploid plants were transferred to MS medium (Murashige and Skoog 1962).

Only embryos bigger than $1 \mathrm{~mm}$, and with developed coleoptile and radicule were divided into four groups that germinated and converted into plants in the following light intensities: $20 \mu \mathrm{mol} \mathrm{m}{ }^{-2} \mathrm{~s}^{-1}, 40 \mu \mathrm{mol} \mathrm{m} \mathrm{m}^{-2} \mathrm{~s}^{-1}, 70 \mu \mathrm{mol} \mathrm{m} \mathrm{m}^{-2} \mathrm{~s}^{-1}$ and $110 \mu \mathrm{mol} \mathrm{m} \mathrm{m}^{-2} \mathrm{~s}^{-1}$ (fluorescent lamps, $36 \mathrm{~W}$, Philips PILA, Netherlands) at 16/8 h light/dark cycle and $20 \pm 2{ }^{\circ} \mathrm{C}$. Haploid plants were acclimated to ex vitro conditions by transferring them to a moist perlite and then to the mixture of soil with sand $(3: 1 \mathrm{v} / \mathrm{v})$ at $20 \pm 2{ }^{\circ} \mathrm{C}$ and light intensity of $110 \mu \mathrm{mol} \mathrm{m} \mathrm{m}^{-2} \mathrm{~s}^{-1}$. After acclimatization, the plants were grown in the greenhouse in natural (solar) light intensity of $800 \mu \mathrm{mol} \mathrm{m} \mathrm{m}^{-2} \mathrm{~s}^{-1}$ during the day and sodium lamps between 6-8 a.m., 6-10 p.m. and on cloudy days, at $21-28 / 17^{\circ} \mathrm{C}$ day/night.

Plant ploidy level in both experiments was evaluated using a flow cytometer MACS Quant (Miltenyi Biotec).

\section{Statistical analysis}

The results were analyzed using two-way ANOVA, implemented in the statistical package STATISTICA 10.0 (Stat-Soft, Inc., USA).

\section{Results}

Experiment 1. The effect of donor plant growth conditions on oat haploid embryo formation and development of haploid and DH plants

Analysis of variance showed that the growth conditions of donor plants affected the haploid embryo formation, but not their further development (Table 1). Genotype had a significant influence on haploid embryo production, germination and development into plants on MS0 medium. Furthermore, the interaction between growth conditions and genotype also affected haploid embryo formation.

The differences in the production success rate of haploid embryos derived from different environmental conditions were apparent. The greenhouse was better for haploid embryo formation than the growth chamber (Table 2). The genotypes grown in the greenhouse formed from 5.1 to $12.2 \%$ of haploid embryos per emasculated florets, whereas 3.2 to $10.1 \%$ in the growth chamber. All the tested genotypes produced more haploid embryos in the greenhouse than in the growth chamber. The most noticeable difference was observed in the SW $081202 \times$ Bingo genotype (10.3 and 4.2\%), while the least significant in the Breton $\times$ Zolak genotype (12.2 and 10.1\%). Additionally, the number of germinated embryos and haploid and DH plants varied between genotypes. The highest frequency of 

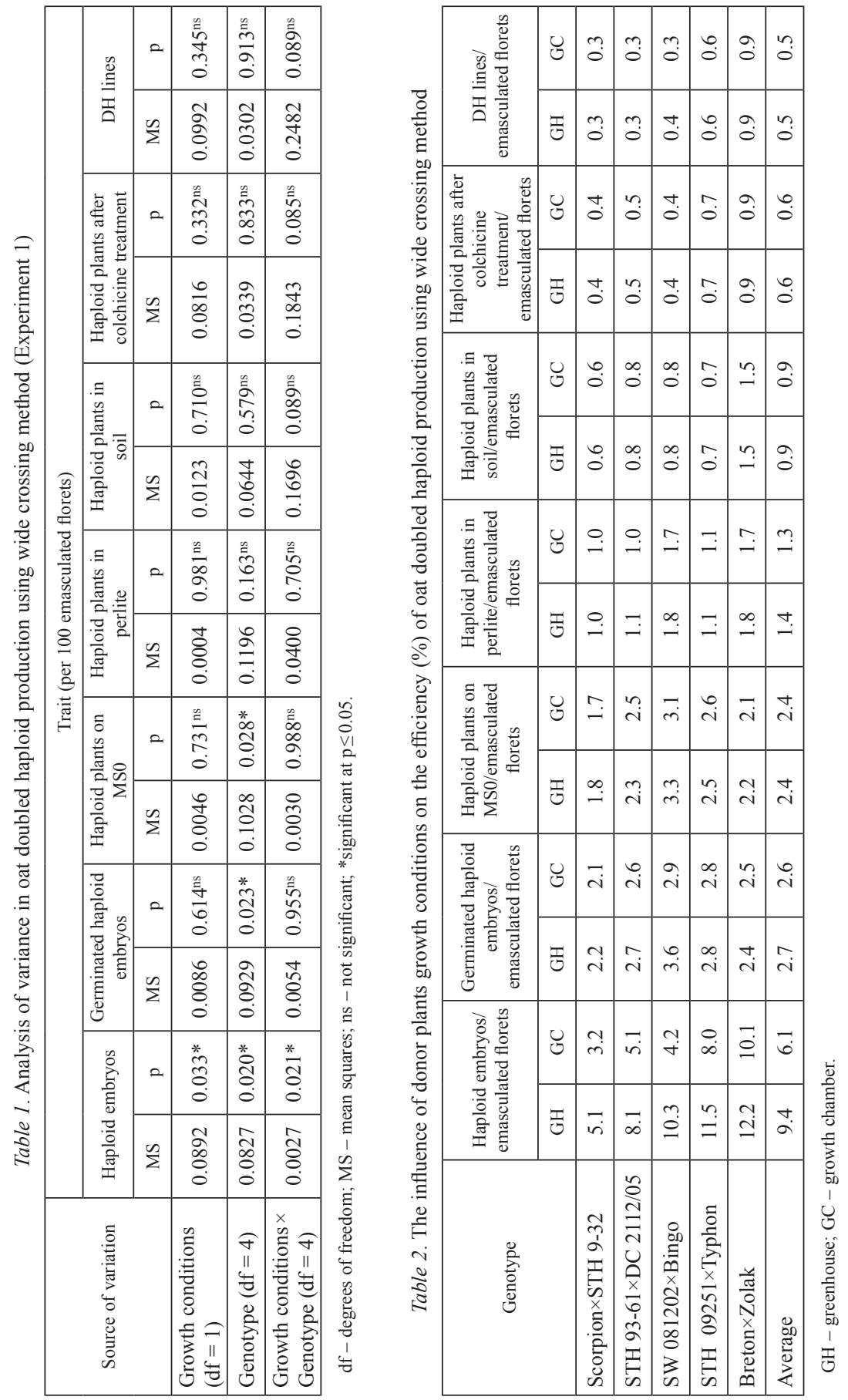


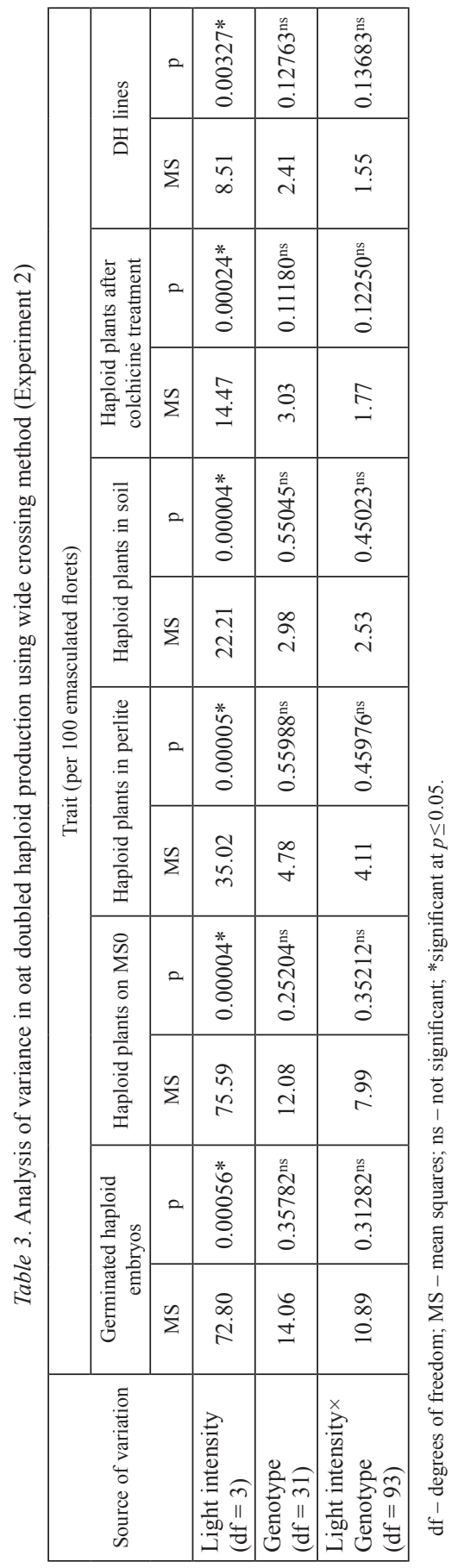


germinated embryos $(3.6 \%$ in the greenhouse and $2.9 \%$ in the growth chamber) and developed haploid plants on MS0 medium (3.3\% in the greenhouse and $3.1 \%$ in the growth chamber) was recorded for the SW $081202 \times$ Bingo genotype. In perlite, two genotypes $($ SW $081202 \times$ Bingo and Breton $\times$ Zolak) reached almost the same percentage of haploid plants per emasculated florets (both $1.8 \%$ in the greenhouse and $1.7 \%$ in the growth chamber). However, further acclimation to natural conditions (replanting to the soil) and chromosome doubling (colchicine treatment) resulted in a higher survival of haploid plants from the Breton $\times$ Zolak than SW $081202 \times$ Bingo genotype. The effectiveness of colchicine treatment was confirmed cytometrically (data not shown). The highest number of fertile DH plants was obtained from Breton $\times$ Zolak, $0.9 \%$, when donor plants were grown in the greenhouse and in the growth chamber.

Experiment 2. The effect of light intensity during in vitro culture on oat haploid embryo formation and development of haploid and DH plants

Two-way ANOVA indicated that the light intensity during in vitro culture had an effect on the following processes: oat haploid embryo germination, haploid plant development on MS0 medium, efficiency of haploid plant acclimatization to the ex vitro conditions (haploid plants in perlite and soil), chromosome doubling procedure and DH line production (Table 3). The analysis did not find any significant differences in the whole procedure of $\mathrm{DH}$ plant production in relation to the genotype. There was also no significant interaction between light intensity and genotypes tested.

Although the embryos were isolated at the same time after pollination with maize, they were at different developmental stages. Approximately thirty percent of them were in the globular stage (smaller than $1 \mathrm{~mm}$ ) (Fig. 1A), while others had clearly visible coleoptile and radicule (bigger than $1 \mathrm{~mm}$ ) (Fig. 1B) and only these embryos were placed under different light intensities.

Although the genotype had no statistically significant influence on the developed haploid embryos, there was an effect observed on the number of embryos formed and their subsequent stages of development (Table $\mathrm{S} 1 *$ ). The highest number of haploid embryos (more than 10\% per emasculated florets) developed from the genotypes: SW $081202 \times$ Bingo, STH $09251 \times$ Typhon, Krezus $\times$ Aragon and Breton $\times$ Zolak. The lowest number of haploid embryos (less then 5\% per emasculated florets) developed from the genotypes: Milenium $\times$ Bingo, Krezus $\times$ Kanton, DH1496/08 $\times$ STH 9-114, STH 8-79 $\times$ Canyon. Embryo germination was the most limiting step of the method applied, as from $7.22 \%$ of developed haploid embryos only $1.72 \%$ germinated successfully. In addition, their acclimation to the ex vitro conditions and colchicine treatment reduced the efficiency of $\mathrm{DH}$ line production to $0.28 \%$. The highest number of $\mathrm{DH}$ lines was obtained from the genotypes: Breton $\times$ Zolak $(0.90 \%)$, Krezus $\times$ Aragon $(0.73 \%)$, STH $9787 \times$ Bingo $(0.66 \%)$ and STH $09251 \times$ Typhon $(0.60 \%)$.

Embryos from all of the light intensity treatments were cultured successfully and the light intensities significantly affected the development of haploid embryos (Table 4). The

*Further details about the Electronic Supplementary Material (ESM) can be found at the end of the article. 

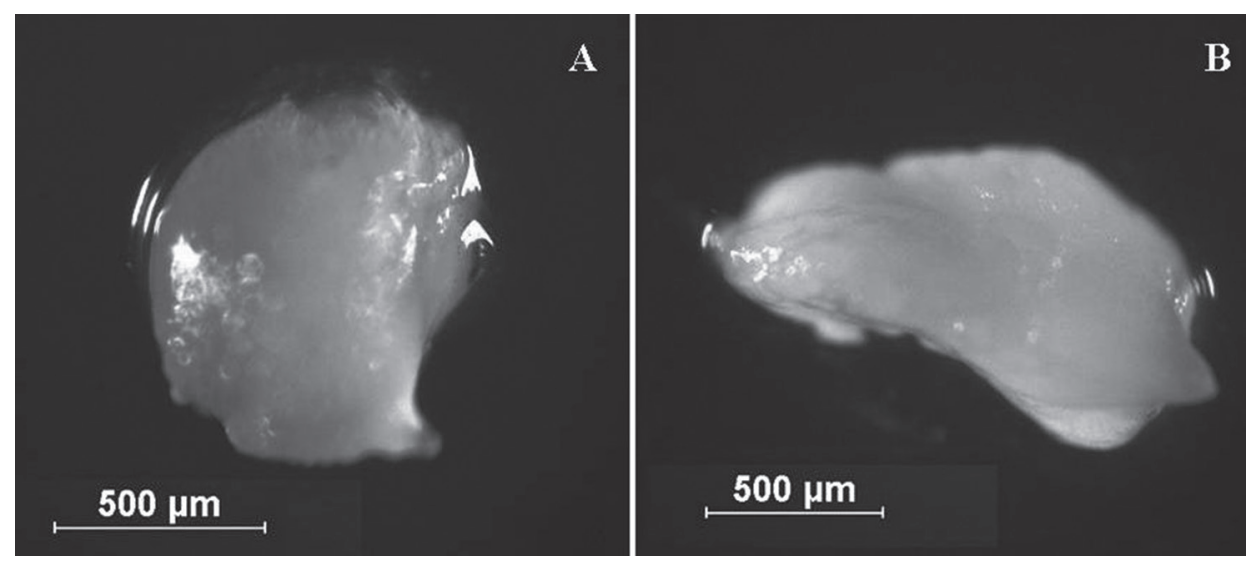

Figure 1. Oat haploid embryos formed by crossing with maize: A - globular stage, B - visible coleoptile and radicule. Embryos isolated from ovaries three weeks after pollination

highest percentage of germinated haploid embryos $(38.9 \%)$, development of haploid plants $(36.4 \%)$, acclimatization in perlite $(22.3 \%)$ and soil $(17.2 \%)$ was obtained at the light intensity of $110 \mu \mathrm{mol} \mathrm{m} \mathrm{m}^{-2} \mathrm{~s}^{-1}$ during culture in vitro compared to the lower light intensities. Moreover, it affected the most the process of chromosome doubling $(13.0 \%)$ and DH line development $(9.2 \%)$. As in the previous experiment, the efficiency of chromosome doubling using colchicine was measured cytometrically (data not shown). The three lower light intensities had nearly the same values of germinated haploid embryos, developed haploid plants and acclimated plants. Light intensities of 20 and $40 \mu \mathrm{mol}$ $\mathrm{m}^{-2} \mathrm{~s}^{-1}$ affected the survival of plants after colchicine treatment and the number of DH lines to a lesser extent when compared to other light intensities. The exposure of haploid embryos and plants to the light intensity of $70 \mu \mathrm{mol} \mathrm{m} \mathrm{m}^{-2} \mathrm{~s}^{-1}$ resulted in a more efficient process of chromosome doubling and $\mathrm{DH}$ line development in comparison to the light intensity of 20 and $40 \mu \mathrm{mol} \mathrm{m} \mathrm{m}^{-2} \mathrm{~s}^{-1}$.

Table 4. The effect of light intensity on the efficiency of oat doubled haploid production using wide crossing method

\begin{tabular}{|c|c|c|c|c|c|c|c|}
\hline $\begin{array}{l}\text { Light intensity } \\
{\left[\mu \mathrm{mol} \mathrm{m}{ }^{-2} \mathrm{~s}^{-1}\right]}\end{array}$ & $\begin{array}{c}\text { Total } \\
\text { haploid } \\
\text { embryos }\end{array}$ & $\begin{array}{l}\text { Germinated } \\
\text { haploid } \\
\text { embryos }\end{array}$ & $\begin{array}{l}\text { Haploid } \\
\text { plants on } \\
\text { MS0 }\end{array}$ & $\begin{array}{l}\text { Haploid } \\
\text { plants in } \\
\text { perlite }\end{array}$ & $\begin{array}{c}\text { Haploid } \\
\text { plants in soil }\end{array}$ & $\begin{array}{c}\text { Haploid plants } \\
\text { after } \\
\text { colchicine } \\
\text { treatment }\end{array}$ & DH lines \\
\hline 20 & 294 & 85 (28.9) & $75(25.5)$ & 39 (13.3) & $24(8.2)$ & $20(6.8)$ & $10(3.4)$ \\
\hline 40 & 296 & $98(33.1)$ & $68(23.0)$ & $36(12.2)$ & $28(9.5)$ & $14(4.7)$ & $9(3.0)$ \\
\hline 70 & 249 & $80(32.1)$ & $74(29.7)$ & $36(14.5)$ & $26(10.4)$ & $23(9.2)$ & $14(5.6)$ \\
\hline 110 & 470 & $183(38.9)$ & $171(36.4)$ & $105(22.3)$ & $81(17.2)$ & $61(13.0)$ & $43(9.2)$ \\
\hline $\begin{array}{c}\text { Total } \\
\text { (average) }\end{array}$ & 1309 & $446(33.3)$ & $388(28.7)$ & $216(15.6)$ & 159 (11.3) & $118(8.4)$ & $76(5.3)$ \\
\hline
\end{tabular}

Data are presented as the total number and followed in parenthesis by the percentages of haploid embryos and plants calculated per 100 of emasculated florets. 
Light intensity did not affect germination of haploid embryos and their development during in vitro culture as significantly as the subsequent stages of $\mathrm{DH}$ line production in ex vitro conditions. This means that the light intensity in our in vitro cultures exerted a secondary effect on the development of plants ex vitro.

\section{Discussion}

Light affects plants in many ways throughout all stages of life, including germination, stem growth, chloroplast development, biosynthesis of chlorophylls and other pigments, circadian rhythm, flowering and others (Han et al. 2007). Plants grow and develop in response to light signals. This process is mediated by a sophisticated network of photoreceptors, among which phytochromes play a key role. Phytochrome-mediated photomorphogenic responses are characterized by many complex relationships between the light input and physiological outputs. Moreover, there are many possible physiological reasons through which environmental factors can affect haploid embryo induction and recovery. High intensity of light may affect the accumulation of photosynthates - resources for haploid embryo development. In the study of Campbell et al. (1998), all of the wheat plants used for haploid induction were grown in the same environmental conditions until the booting stage. Therefore, the differences in photosynthate accumulation, affecting embryo recovery, would have had to occur in the time between the transfer of the plants to the growth cabinets and embryo survival. Alterations in light intensity and temperature may change the environment of fertilization tract in parental female wheat. This, in turn, can affect the ability of maize pollen to successfully fertilize wheat ovules. Alternatively, different environmental conditions may affect the level of endogenous plant growth regulators or cell sensitivity to them, leading to subsequent improvements in fertilization and/ or embryo survival rates. The authors have clearly established that environmental factors can exert a significant influence on wheat haploid recovery. This study indicates that the seasons of the year of low light intensity or high temperatures should be avoided in wheat DH programmes using the wheat $\times$ maize method. A better understanding of the physiology underlying these results will enable manipulation of environmental conditions employed during wheat $\times$ maize crosses and other wide cereal crosses, which may lead to subsequent improvements in the overall efficiency of such systems. Campbell et al. (1998) tested three different light intensities $\left(300,500\right.$ or $\left.1000 \mu \mathrm{mol} \mathrm{m} \mathrm{m}^{-2} \mathrm{~s}^{-1}\right)$ on haploid embryo recovery during the growth of donor plants. These authors found that not only light intensity but also the genotype had an influence on embryo recovery, however, embryo recovery was higher under the highest light intensity. In the study of Campbell et al. (2001), haploid embryo survival of the cultivar Karamu was significantly affected by the light intensity, as $34 \%$ of pollinated florets produced haploid embryos at the high light intensity $\left(750 \mu \mathrm{mol} \mathrm{m} \mathrm{m}^{-2} \mathrm{~s}^{-1}\right)$ compared to only $4 \%$ of pollinated florets that produced hap-

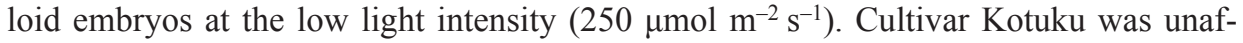
fected by different light intensities, as 33\% of pollinated florets produced haploid embryos at the high light intensity and $38 \%$ at the low light intensity. 
In our experiment, higher efficiency of haploid embryo formation and their development was obtained when donor plants were grown in the greenhouse conditions under natural light during the day $\left(800 \mu \mathrm{mol} \mathrm{m} \mathrm{m}^{-2} \mathrm{~s}^{-1}\right)$ when compared to the growth chamber with fully artificial light $\left(450 \mu \mathrm{mol} \mathrm{m} \mathrm{m}^{-2} \mathrm{~s}^{-1}\right)$. Worth noting is the fact that growing conditions of donor plants affected all stages of $\mathrm{DH}$ plant production, not only haploid embryo formation.

Genotypic variation in response of different oat lines have been reported by Rines (2003), but they may be obscured by the reaction of lines to the growth conditions applied. In general, the more vigorous the plants, the higher frequency and quality of embryos recovered.

Similarly, in our investigations, the interaction between the genotypes and donor plant growing conditions was also observed. More haploid embryos were induced from donor plants grown in the greenhouse $(9.4 \%)$ than in the growth chamber $(6.1 \%)$.

Light has also affected the development of haploid embryos. Campbell et al. (1998) found that the frequency of haploid embryo recovery in wheat $\times$ maize crosses was significantly influenced by the temperature, while various light intensities exerted even greater effect. Cotyledonary and germinated embryos show photosynthetic ability, although pretreatment with $100 \mu \mathrm{mol} \mathrm{m}^{-2} \mathrm{~s}^{-1}$ light intensity accelerated this process (Afreen et al. 2002). Therefore, their results suggest that the light intensity of 100-150 $\mu \mathrm{mol}$ $\mathrm{m}^{-2} \mathrm{~s}^{-1}$ and an increased $\mathrm{CO}_{2}$ concentration $\left(1100 \mu \mathrm{mol} \mathrm{mol}^{-1}\right)$ are required for the development of plantlets from cotyledonary stage somatic embryos under photoautotrophic conditions.

Our study also clearly showed that the light intensity of $110 \mu \mathrm{mol} \mathrm{m} \mathrm{m}^{-2} \mathrm{~s}^{-1}$ during in vitro culture resulted in the highest rate of embryo germination $(38.9 \%)$ and conversion to plants $(36.4 \%)$ compared to lower light intensities.

In conclusion, the results of our research show that the induction of haploid embryos and their subsequent survival in oat $\times$ maize crosses can be significantly affected by the intensity of light. The effect of light intensity depends on the genotype only during haploid embryo formation. The influence of light intensity during subsequent stages of DH line production was independent of the genotype. The effect of light intensity on haploid embryo formation and the production of DH plants observed in this study may be relevant to wide crosses of different cereals, as it seems that haploid embryo development can be affected by the growing conditions of the donor plant and light intensity during in vitro culture.

\section{Acknowledgement}

The research was funded by the Ministry of Agriculture and Rural Development, grant No HORhn-801-4/12.

\section{Conflict of Interest}

The authors declare that they have no conflict of interest. 


\section{References}

Afreen, F., Zobayed, S.M.A., Kozai, T. 2002. Photoautotrophic culture of Coffea arabusta somatic embryos: Photosynthetic ability and growth of different stage embryos. Ann. Bot. 90:11-19.

Campbell, A.W., Griffin, W.B., Conner, A.J., Rowarth, J.S., Burritt, D.J. 1998. The effects of temperature and light intensity on embryo numbers in wheat doubled haploid production through wheat $\times$ maize crosses. Ann. Bot. 82:29-33.

Campbell, A.W., Griffin, W.B., Burritt, D.J., Conner, A.J. 2001. The importance of light intensity for pollen tube growth and embryo survival in wheat $\times$ maize crosses. Ann. Bot. 87:517-522.

Chen, M., Chory, J., Fankhauser, Ch. 2004. Light signal transduction in higher plants. Annu. Rev. Genet. 38:87-117.

Germana, M.A. 2011. Gametic embryogenesis and haploid technology as valuable support to plant breeding. Plant Cell Rep. 30:839-857.

Han, Y.J., Song, P.S., Kim, J.I. 2007. Phytochrome-mediated photomorphogenesis in plants. J. Plant Biol. 50:230-240.

Hoagland, D.R., Arnon, D.I. 1938. A water culture method for growing plants without soil. Circ. Univ. Calif, Agric. Exp. Stn. No. 347.

Ishii, T., Tanaka, H., Eltayeb, A.E., Tsujimoto, H. 2013. Wide hybridization between oat and pearl millet belonging to different subfamilies of Poaceae. Plant Reprod. 26:25-32.

Kiviharju, E. 2009. Anther culture derived double haploids in oat. In: Touraev, A. et al. (eds), Advances in Haploid Production in Higher Plants. Springer Science+Business Media B.V., Berlin, Germany. pp. 171-178.

Kiviharju, E., Moisander, S., Laurila, J. 2005. Improved green plant regeneration rates from oat anther culture and the agronomic performance of some DH lines. Plant Cell Tiss. Org. Cult. 81:1-9.

Marcińska, I., Nowakowska, A., Skrzypek, E., Czyczyło-Mysza, I. 2013. Production of doubled haploids in oat (Avena sativa L.) by pollination with maize (Zea mays L.). Central Eur. J. of Biol. 8:306-313.

Murashige, T., Skoog, F. 1962. A revised medium for rapid growth and bioassays with tobacco tissue cultures. Physiologia Plantarum 15:473-497.

Nowakowska, A., Skrzypek, E., Marcińska, I., Czyczyło-Mysza, I., Dziurka, K., Juzoń, K., Cyganek, K., Warchoł, M. 2015. Application of chosen factors in the wide crossing method for oat double haploids production. Open Life Sci. 10:112-118.

Rines, H.W. 2003. Oat haploids from wide hybridization. In: Małuszyński, M. et al. (eds), Double Haploid Production in Crop Plants. Kluwer Academic Publishers. Dordrecht, The Netherlands, pp. 155-159.

Rubtsova, M., Gnad, H., Melzer, M., Weyen, J., Gils, M. 2013. The auxins centrophenoxine and 2,4-D differ in their effects on non-directly induced chromosome doubling in anther culture of wheat (T. aestivum L.). Plant Biotechnol. Rep. 7:247-255.

Sidhu, P.K., Davies, P.A. 2009. Regeneration of fertile green plants from oat isolated microspore culture. Plant Cell Rep. 28:571-577.

Sidhu, P.K., Howes, N.K., Aung, T., Zwer, P.K., Davies, P.A. 2006. Factors affecting haploid production following oat $\times$ maize hybridization. Plant Breeding 125:1-6.

Wang, X.Z., Hu, H. 1984. The effect of potato II medium for 279 triticale anther culture. Plant Sci. Lett. 36:237-239.

Warchoł, M., Skrzypek, E., Nowakowska, A., Marcińska, I., Czyczyło-Mysza, I., Dziurka, K., Juzoń, K., Cyganek, K. 2016. The effect of auxin and genotype on the production of Avena sativa L. doubled haploid lines. Plant Growth Regul. 78:155-165.

\section{Electronic Supplementary Material (ESM)}

Electronic Supplementary Material (ESM) associated with this article can be found at the website of CRC at http://www.akademiai.com/content/120427/

Electronic Supplementary Table S1. The effect of oat genotype on the efficiency of oat doubled haploid production using wide crossing method 